Research Article

\title{
Field Experimental Study on the Broken Rock Zone of Surrounding Rock and the Rock Borehole Shear Tests of the Large Deformation Tunnel
}

\author{
Guansheng Han, ${ }^{1}$ Bo Meng $\mathbb{D}^{1,2}$ Hongwen Jing $\mathbb{D}^{1},{ }^{1}$ and Jiangyu Wu ${ }^{1}$ \\ ${ }^{1}$ State Key Laboratory for Geomechanics and Deep Underground Engineering, China University of Mining and Technology, \\ Xuzhou, Jiangsu 221116, China \\ ${ }^{2}$ School of Mechanics \& Civil Engineering, China University of Mining \& Technology, Xuzhou, Jiangsu 221116, China
}

Correspondence should be addressed to Bo Meng; wangk@cumt.edu.cn

Received 15 April 2019; Revised 3 October 2019; Accepted 23 October 2019; Published 23 November 2019

Academic Editor: Veronica Calado

Copyright (c) 2019 Guansheng Han et al. This is an open access article distributed under the Creative Commons Attribution License, which permits unrestricted use, distribution, and reproduction in any medium, provided the original work is properly cited.

\begin{abstract}
A large deformation tunnel in LIXIANG railway, named Zhongyi tunnel is located in Southwest of China, was taken for the engineering background. The field experiments of the broken rock zone and the borehole shear test were conducted. The results show that the range of the broken rock zone of the test sections is 4.20 4.45 meters. The cohesive force and the internal friction angle of the test sections are $221.4 \sim 224 \mathrm{kPa}$ and $14.25 \sim 15.14^{\circ}$, respectively. The test results are in good agreement with the status of the surrounding rock. The surrounding rock is mainly composed of shale, which is badly broken, and the integrity and the stability are poor. In this study, the reasons for the deformation and instability of the tunnel are analyzed combined with the in situ tests and the site condition, and the suggestions for the tunnel support are put forward. This study is of great significance to ensure the safety of the constructors and can improve the service years of the tunnel. In addition, it can provide reference for the same type of the tunnel construction.
\end{abstract}

\section{Introduction}

The large deformation of the tunnel not only seriously affects the construction progress and the construction cost of the tunnel but also poses a great threat to the safety of the constructors. Therefore, the large deformation of the tunnel has been a difficult problem that plagues the construction of underground engineering [1-5]. In order to solve this key problem, it is very important to carry out field experiments in large distortion tunnels [6].

Many previous researchers have provided qualitative descriptions in terms of a large deformation tunnel. Tjongkie proposed that the mechanism of convergence deformation of surrounding rock should include five aspects: plastic wedge, flow deformation, swelling, dilatation, and deflection of surrounding rock [7]. Anagnostou proposed that large deformation mainly depends on rock strength and overburden thickness [8]. In principle, it can occur in any type of rock mass. Singh et al. pointed out that large deformation occurs on the premise of weak surrounding rock combined with high in situ stress [9]. Jiang et al. proposed a theoretical method for predicting the development of a plastic zone and loosening pressure in soft rock tunnels and discussed the influence of the mechanical properties of soft rock on loosening pressure [10]. Theoretical analysis, numerical simulation, and field monitoring were employed to investigate the surrounding rock stress and displacement state in the Dongsong hydropower station by Zhang et al [11]. Through the theoretical study of the surrounding rock stress field and analysis of the space-time effect of numerical simulation and real-time feedback of field monitoring, the whole process of excavation and support of a large deformation tunnel in soft rock was studied. Relevant works also include the research performed by Yassaghi and Salari- 
Rad [12], Bizjak and Petkovšek [13], and Janda et al [14]. However, the above studies rarely involve the broken rock zone test and the rock borehole shear tests of large deformation tunnels. This paper takes a large deformation tunnel as background, and the field experiments of the broken rock zone and the borehole shear test were conducted.

LIXIANG railway is located in the southwest of Yunnan Province (China), starting from Lijiang station, crossing Jinsha River and then passing Xiaozhongdian to the final destination Shangri-La. The total length is 139.686 kilometers (Figure 1).

There are 20 new tunnels with a total length of 92.554 kilometers to be built, which are accounting for $66.3 \%$ of the total length of the line. The Zhongyi tunnel is one of the 20 tunnels, which is the longest tunnel with a length of 14.745 kilometers. Therefore, the Zhongyi tunnel is also the most difficult tunnel for construction. What is more, a large deformation occurs during the excavation of the Zhongyi tunnel (Figure 2), and the large distortion section is located in the western piedmont fault of Jade Dragon Snow Mountain. The integrity and stability of the surrounding rock in the test section are poor, and the grade of surrounding rock is grade $\mathrm{V}$. The groundwater is developed, and there is a fissure water outflow at the top heading of a tunnel face. This paper mainly provides suggestions for the support scheme of the large distortion tunnel through field experiments of the broken rock zone and borehole shear test.

\section{Broken Rock Zone Tests}

It has widely been recognized by industry insiders since the surrounding rock support theory based on broken rock zone has been put forward [15], and the broken rock zone is widely used in underground tunnel excavation projects such as coal mine roadway [16], railway tunnel [17], and highway tunnel [18]. The method for broken rock zone tests has been progressing. Song et al. [19] proposed a new measuring method for broken rock zone tests by using ground-penetrating radar. And a panoramic borehole camera technology and digital image processing method were developed by constructing a system composed of hardware and software [20]. In this study, the ground-penetrating radar was adopted as the method for determining the broken rock zone.

2.1. Measuring Principle and Equipment. The propagation velocity of sound waves in rock will be reduced by the development of fracture, the decrease in density, and the increase in acoustic impedance. Therefore, for the same type of rock mass, we can judge the extent of the damage of the surrounding rock through the wave velocity. By measuring the wave velocity of rock mass at different depths, the curve of the relationship between the wave velocity and the depth of the hole is drawn. Then, the thickness of the broken rock zone can be determined according to the attenuation range of wave velocity in the above curve. The RSM-SY6 acoustic wave tester is selected as the test equipment in this chapter, as shown in Figure 3.

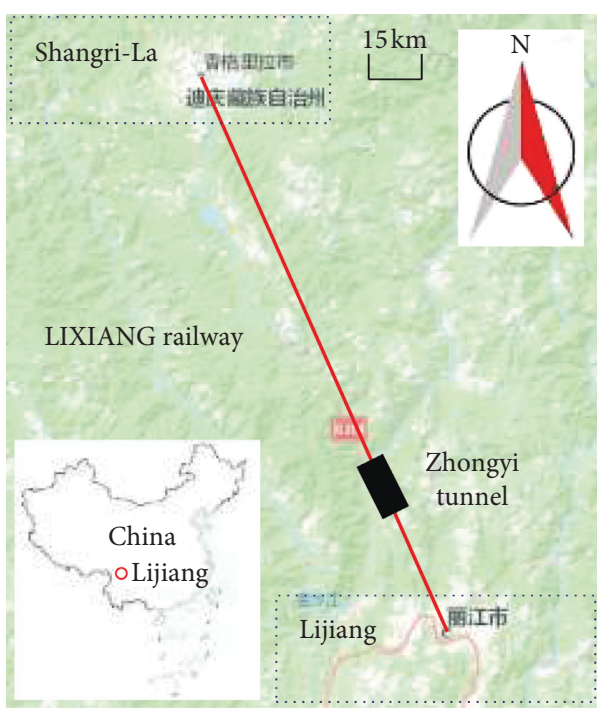

Figure 1: Lijiang to Shangri-La railway.

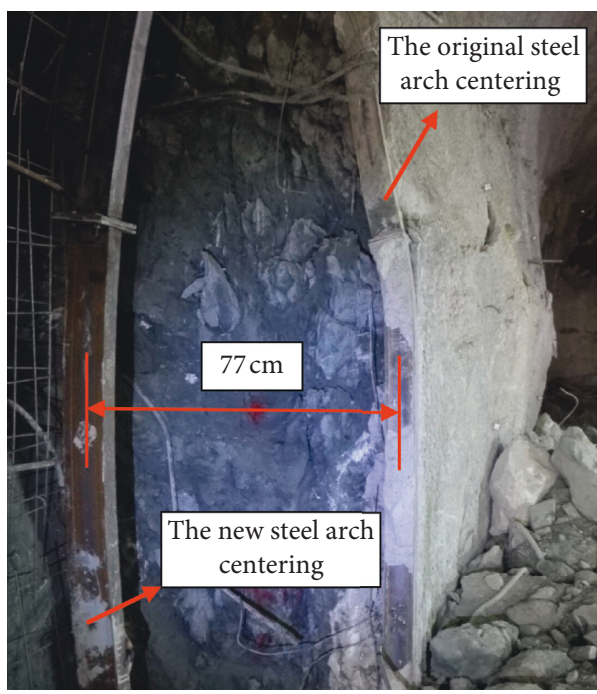

FIgure 2: The large distortion section.

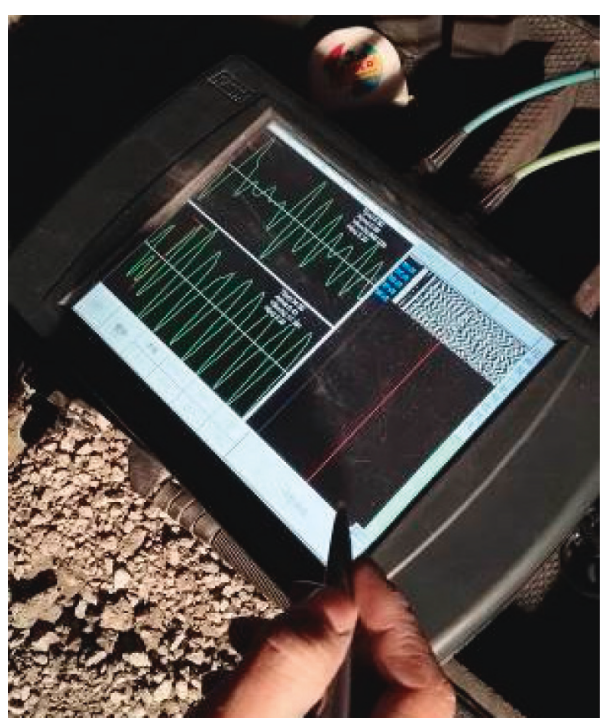

Figure 3: The RSM-SY6 acoustic wave tester. 
2.2. Arrangement of Measuring Points. According to the test plan, the broken rock zone tests are carried out on two sections of ZHONGYI tunnel: distance kilometer (DK) $41+990$ and DK42 + 000, respectively.

A total of four test points, which are A, B, C, and D, respectively, are considered. The test point $\mathrm{A}$ is arranged in the left side of the section DK41 +990, the test point B is arranged in the right side of the section DK41 + 990, the test point $C$ is arranged in the left side of the section DK $42+000$, and the test point $\mathrm{D}$ is arranged in the right side of the section DK42+000. Each of the test point is arranged with a pair of measuring holes. The measuring holes are downward sloping $3 \sim 5^{\circ}$ to ensure the hole can be filled with clear water; the diameter is $5.5 \mathrm{~cm}$, and the depth is $10 \mathrm{~m}$ (Figure $4(\mathrm{a})$ ). The relative distance of a pair of measuring holes is $80 \mathrm{~cm}$ and parallel to each other. The PVC tube with a diameter of $5 \mathrm{~cm}$ is placed in the hole to prevent the rock wall from collapsing. In addition, the clear water is filled in the hole to ensure a good result of ultrasonic coupling during the test. The drill holes in the section DK41 +990 are arranged as shown in Figures 4(b) and 4(c).

\subsection{Results of the Broken Rock Zone Tests}

2.3.1. Section of $D K 41+990$. The relationship between the wave velocity and the depth of the drilling hole of the test point A is shown in Figure 5.

The wave velocity fluctuates greatly for the drill hole depth $1 \sim 4.0 \mathrm{~m}$, which indicates that there are some complex cracks in the surrounding rock, and the average wave velocity is $2.05 \mathrm{~km} / \mathrm{s}$. The wave velocity has risen by leaps and bounds for the drill hole depth $4.1 \mathrm{~m}$, which shows the depth reaches $4.1 \mathrm{~m}$ that is called a demarcation point and the surrounding rock formed a collapsed arch here. The wave velocity maintains a stable state for the drill hole depth $4.2 \sim 10 \mathrm{~m}$, and the average wave velocity is $2.84 \mathrm{~km} / \mathrm{s}$. The average value of the wave velocity of drill hole depth $4.2 \sim 10 \mathrm{~m}$ is $38.5 \%$ larger than that of drill hole depth $1 \sim 4.0 \mathrm{~m}$. The above conclusion shows the broken rock zone of the test point $\mathrm{A}$ is at $4.1 \mathrm{~m}$.

The relationship between the wave velocity and the depth of the drilling hole of the test point B is shown in Figure 6. The variation of the wave velocity for test point $B$ with the drill hole depth is similar to that for A. For the drill hole depth $1 \sim 4.2 \mathrm{~m}$, the curve is defined as undulating sections, and the average wave velocity is $2.21 \mathrm{~km} / \mathrm{s}$. When the drill hole depth reaches $4.3 \mathrm{~m}$, the wave velocity increases rapidly. For the drill hole depth $4.4 \sim 10 \mathrm{~m}$, the curve is defined as the stationary section, and the average wave velocity is $2.86 \mathrm{~km} /$ $\mathrm{s}$. The average value of the wave velocity of drill hole depth $4.4 \sim 10 \mathrm{~m}$ is $29.4 \%$ larger than that of drill hole depth $1 \sim 4.2 \mathrm{~m}$. The above conclusion shows the broken rock zone of the test point $B$ is at $4.3 \mathrm{~m}$.

2.3.2. Section of $D K 42+000$. Figure 7 presents the relationship between the wave velocity and the depth of the drill hole depth of the test point $\mathrm{C}$. When drill hole depth is $1 \sim 4.3 \mathrm{~m}$, the curve is defined as the undulating section, and the average wave velocity is $2.10 \mathrm{~km} / \mathrm{s}$. When the drill hole depth reaches $4.4 \mathrm{~m}$, the wave velocity increases rapidly. When the drilling depth is $4.5 \sim 10 \mathrm{~m}$, the curve is defined as the stationary section, and the average wave velocity is $2.90 \mathrm{~km} / \mathrm{s}$. The average wave velocity of drill hole depth $4.5 \sim 10 \mathrm{~m}$ is $38.1 \%$ larger than that of drill hole depth $1 \sim 4.3 \mathrm{~m}$. The above conclusions show that the broken rock zone of the test point $\mathrm{C}$ is at $4.4 \mathrm{~m}$.

Figure 8 displays the relationship between the wave velocity and the depth of the drilling hole of the test point $\mathrm{D}$. For the drill hole depth 1 4.4 m, the curve is defined as the undulating section, and the average wave velocity is $2.22 \mathrm{~km} /$ $\mathrm{s}$. When the drill hole depth reaches $4.5 \mathrm{~m}$, the wave velocity increases rapidly. For the drill hole depth $4.6 \sim 10 \mathrm{~m}$, the curve is defined as the stationary section, and the average wave velocity is $2.91 \mathrm{~km} / \mathrm{s}$. The average value of the wave velocity of the drill hole depth $4.6 \sim 10 \mathrm{~m}$ is $31.1 \%$ larger than that of the drill hole depth $1 \sim 4.4 \mathrm{~m}$. The above conclusion shows the broken rock zone of the test point $\mathrm{D}$ is at $4.5 \mathrm{~m}$.

\subsubsection{Summary of the Results for Broken Rock Zone Tests.} The results of the 4 test points $A \sim D$ are shown in Table 1 . The average value of the broken rock zone obtained on both sides of a certain section was taken as the final result of the certain section. The broken rock zones are $4.2 \mathrm{~m}$ and $4.45 \mathrm{~m}$ for the sections DK41 + 990 and DK42 + 000, respectively.

The strength of surrounding rock is the main factor that can determine the stability of the tunnel. After the tunnel excavation, the stress redistribution causes large deformation and damage in surrounding rock, which forms a broken rock zone. The broken rock zone continues to expand with a certain range in the absence of support or support unreasonable. Eventually, it leads to a large deformation in the underground engineering.

\section{Borehole Shear Test}

Handy and Fox [21] proposed the concept of the borehole shear test and developed the related experimental equipment. The borehole shear test results do not need empirical formula fitting correction, and it has the advantages of convenient operation, high repeatability, short test time, and so on $[22,23]$. The borehole shear test is suitable for clay, sand, and soft rock, and especially suitable for the area where the rock mass is broken; the drill core is difficult to be taken [24]. In the past 40 years, the research on borehole shear tests is not uncommon. The borehole shear tests have been applied to in situ testing of shear stress of friable loess [25], stiff soil [26], unsaturated soil [27], marine clay [28], and residual soil [29].

3.1. Measuring Principle and Equipment. On the basis of summing up the testing methods for engineering mechanical properties of rock mass for many years, Handy and Fox [21] developed a rock borehole shear test apparatus, as shown in Figure 9. The rock borehole shear test apparatus can apply the normal stress up to $80 \mathrm{MPa}$ and the shear stress up to $50 \mathrm{MPa}$ to the hole wall. The specific operation processes are as follows: determining the shear stress of 


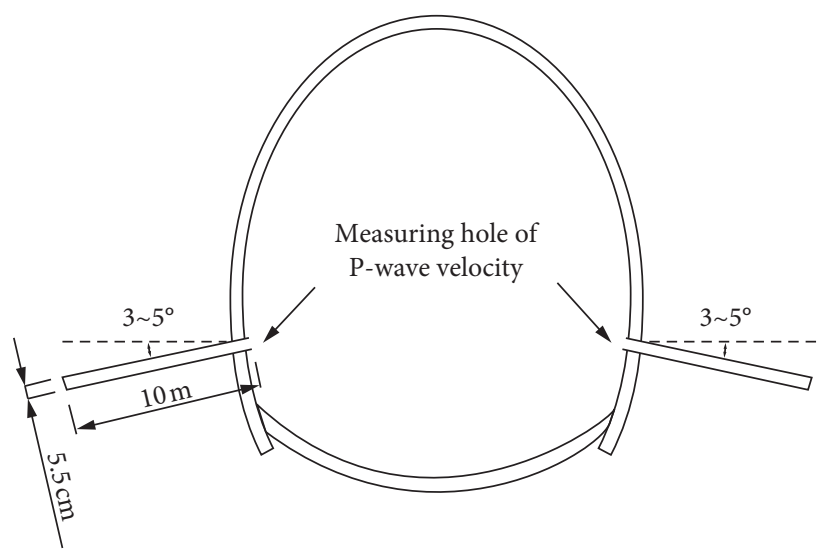

(a)

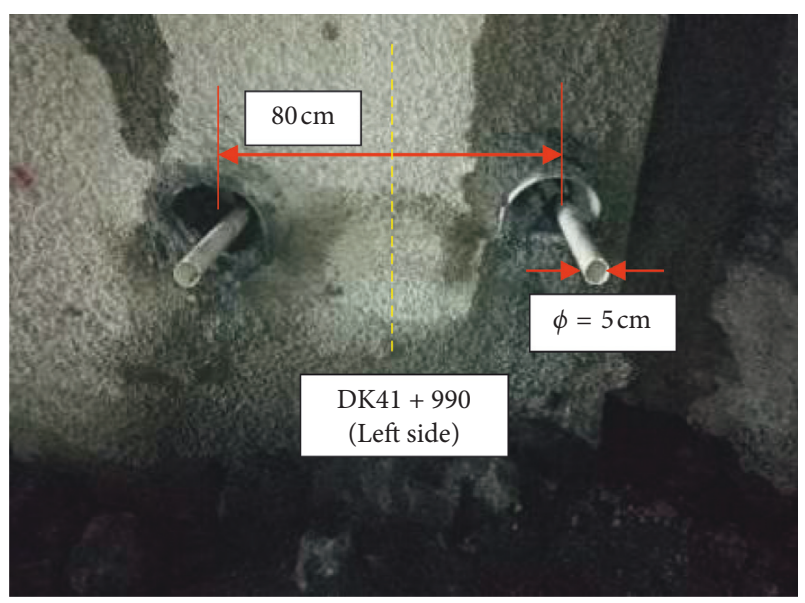

(b)

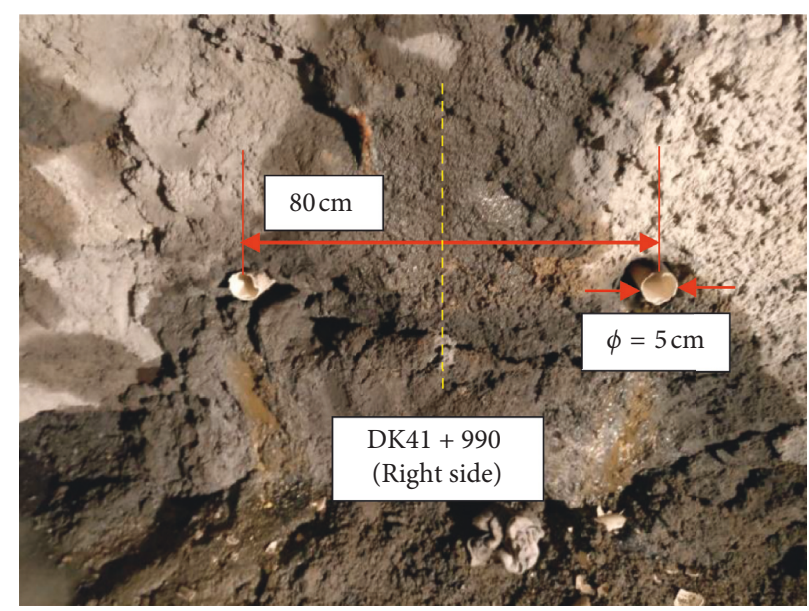

(c)

Figure 4: Arrangement of measuring points of the broken rock zone test.

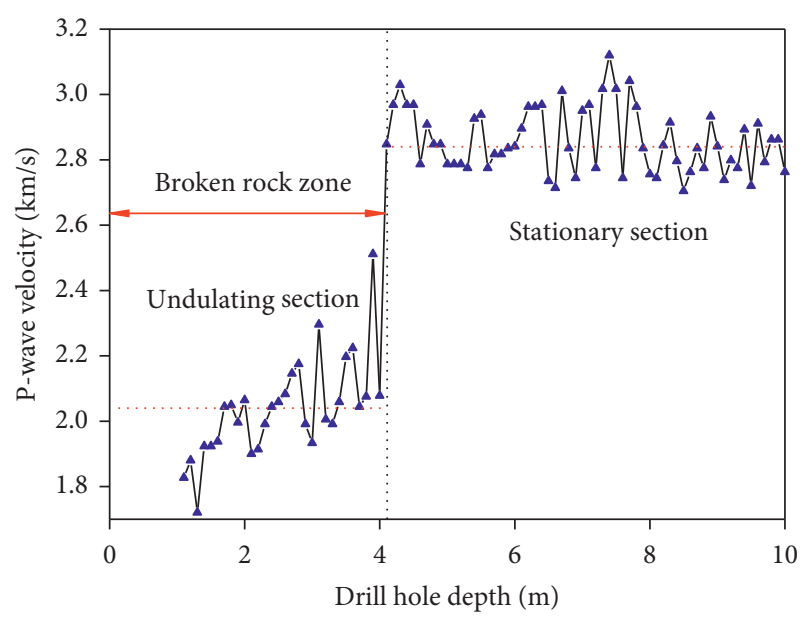

FIGURE 5: The relationship between the wave velocity and the depth of the drilling hole of the test point A.

surrounding rock under different normal stresses by the borehole shear test apparatus firstly, and then, obtaining the cohesive force and the internal friction angle of the surrounding rock according to the Coulomb criterion.

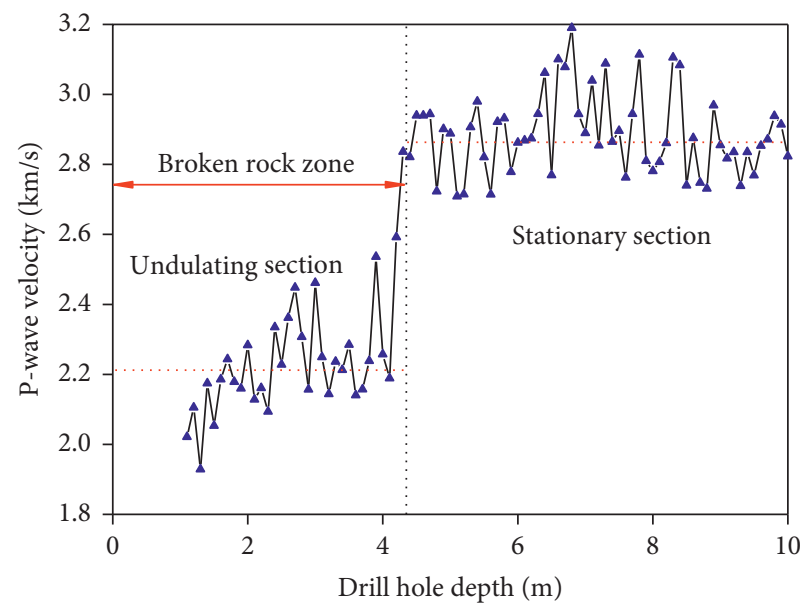

Figure 6: The relationship between the wave velocity and the depth of the drilling hole of the test point $\mathrm{B}$.

3.2. Arrangement of Measuring Points. The borehole shear tests include four test points. The test points \#1 and \#2 are arranged in the tunnel face of the section DK41 +990 (Figure 10(a)), and the test points \#3 and \#4 are arranged in 


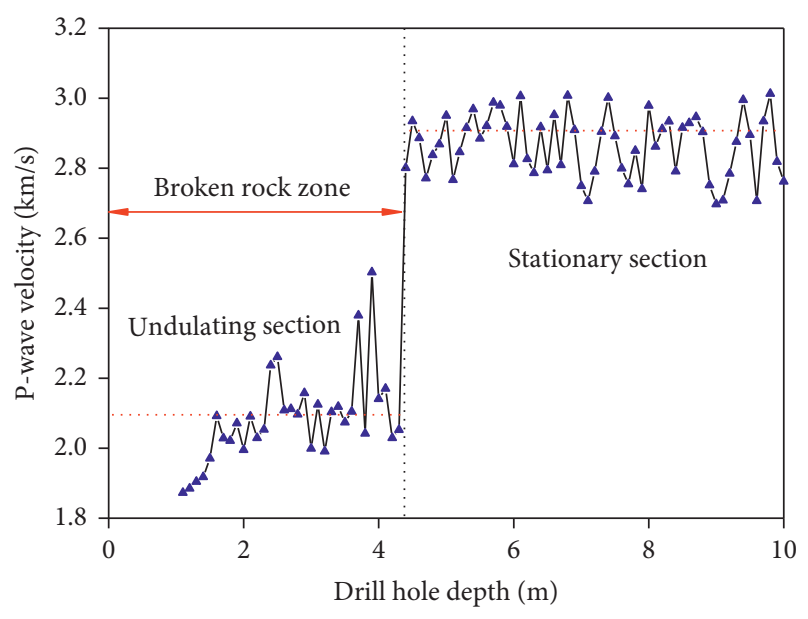

FIGURE 7: The relationship between the wave velocity and the depth of the drilling hole of the test point C.

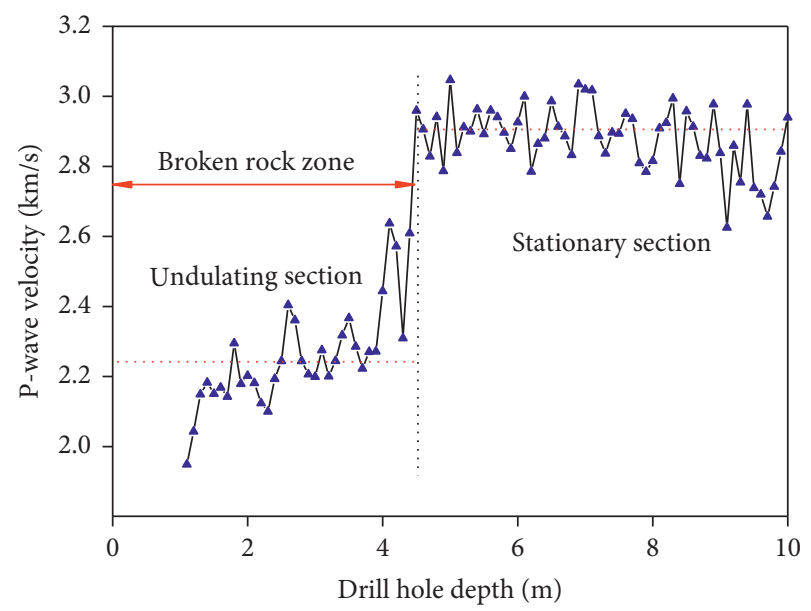

FIGURE 8: The relationship between the wave velocity and the depth of the drilling hole of the test point $\mathrm{D}$.

TABLE 1: The results of broken rock zone tests.

\begin{tabular}{lccc}
\hline $\begin{array}{l}\text { DK (distance } \\
\text { kilometer) }\end{array}$ & $\begin{array}{c}\text { Number of } \\
\text { measuring points }\end{array}$ & $\begin{array}{c}\text { Broken rock } \\
\text { zone (meter) }\end{array}$ & $\begin{array}{c}\text { Average } \\
\text { (meter) }\end{array}$ \\
\hline \multirow{2}{*}{$41+990$} & A & 4.10 & 4.20 \\
\multirow{4}{*}{$42+000$} & B & 4.30 & \\
& C & 4.40 & 4.45 \\
\hline
\end{tabular}

the tunnel face of the section DK42 +000 . In addition, the measuring holes are upward sloping $3 \sim 5^{\circ}$ to keep the holes dry and clean. The hole diameter is $80 \mathrm{~mm}$ (Figure 10(b)), and the hole depth is $5 \mathrm{~m}$.

\subsection{Results of the Borehole Shear Tests}

3.3.1. Section of $D K 41+990$. The relationship between the shear stress and normal stress of the test point \#1 and test point \#2 is shown in Figures 11 and 12, respectively, and the specific parameters are shown in Table 2. From Figures 11

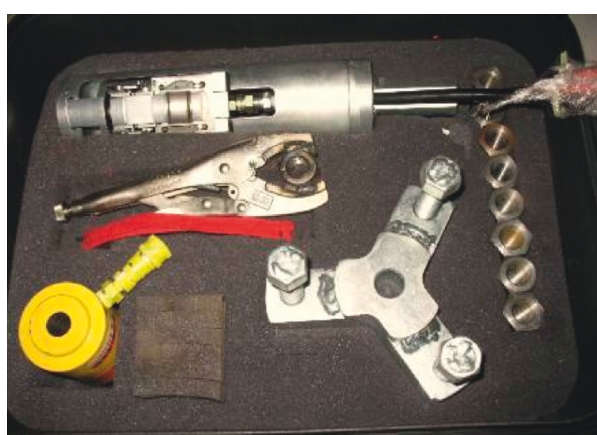

(a)

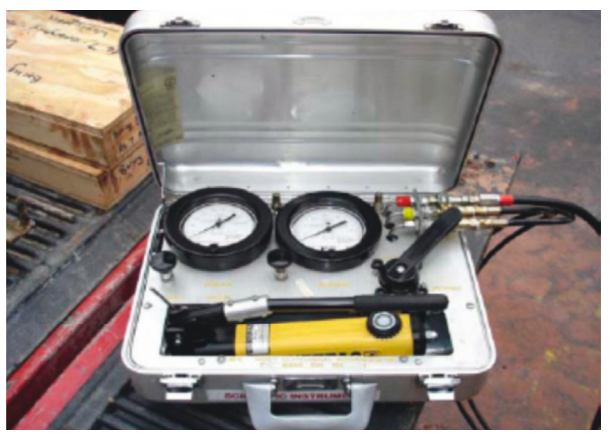

(b)

FIgURE 9: Rock borehole shear test apparatus: (a) direct shear apparatus; (b) lifting jack.

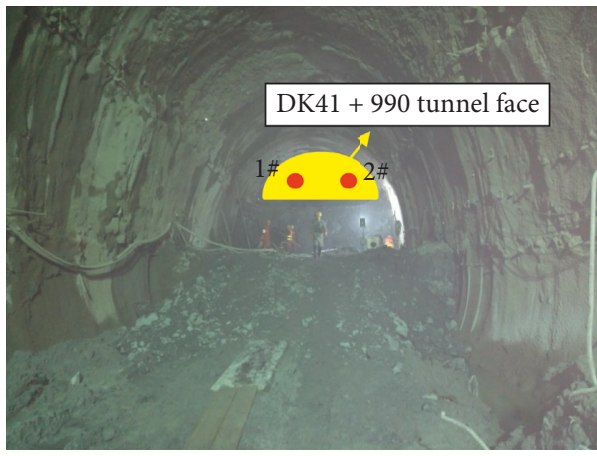

(a)

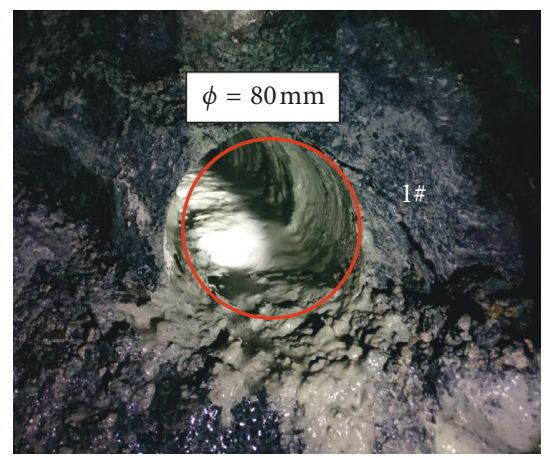

(b)

FIGURE 10: Arrangement of measuring points of the borehole shear test. 


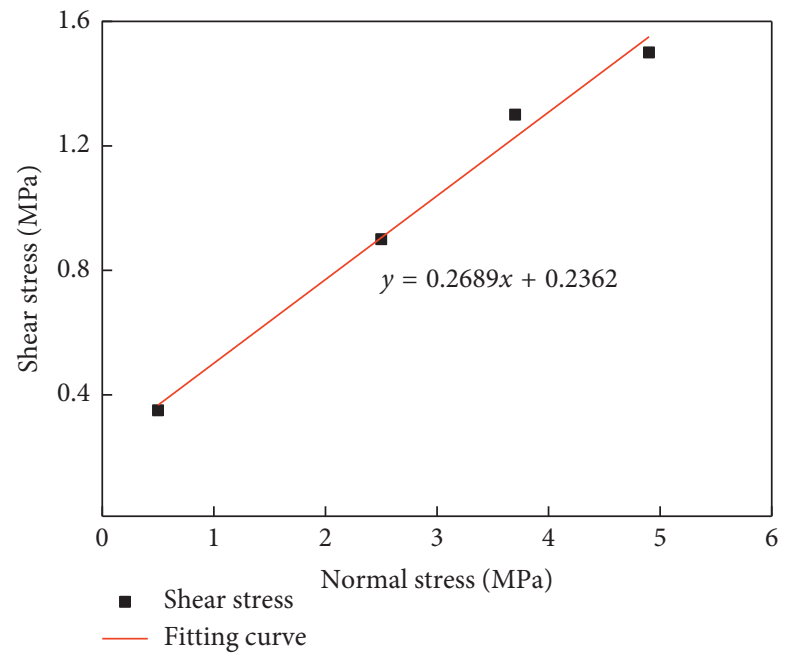

FIgURE 11: The relationship between the shear stress and the normal stress of the test point \#1.

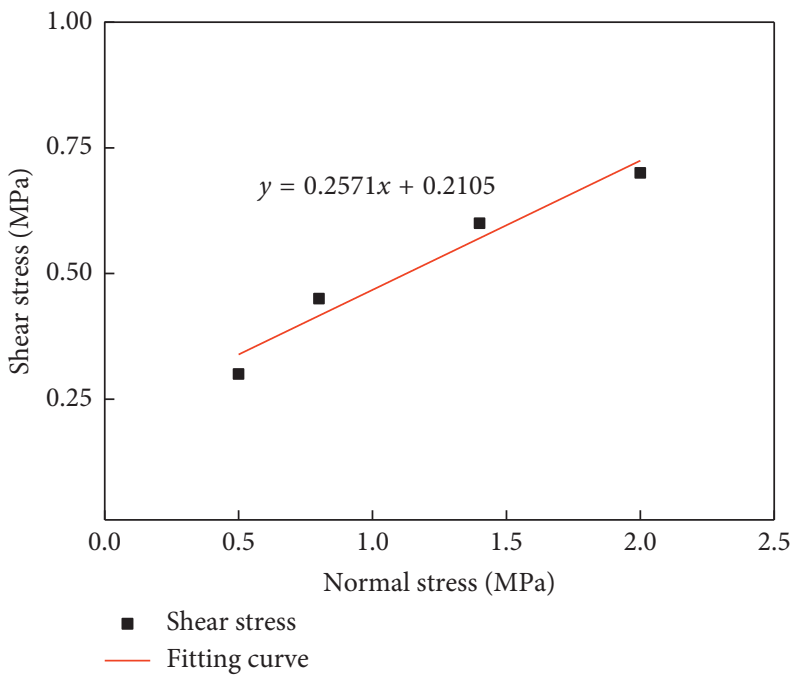

FIgURE 12: The relationship between the shear stress and the normal stress of the test point \#2.

TABLE 2: The results of borehole shear tests.

\begin{tabular}{|c|c|c|c|c|c|c|}
\hline $\begin{array}{l}\text { Number of measuring } \\
\text { points }\end{array}$ & $\begin{array}{l}\text { Normal stress } \\
(\mathrm{MPa})\end{array}$ & $\begin{array}{l}\text { Shear stress } \\
(\mathrm{MPa})\end{array}$ & $\begin{array}{c}\text { Number of measuring } \\
\text { points }\end{array}$ & $\begin{array}{c}\text { Normal stress } \\
(\mathrm{MPa})\end{array}$ & $\begin{array}{l}\text { Shear stress } \\
(\mathrm{MPa})\end{array}$ & Notes \\
\hline \multirow{4}{*}{$\# 1$} & 0.5 & 0.35 & \multirow{4}{*}{$\# 2$} & 0.5 & 0.3 & \multirow{4}{*}{ DK41 + 990} \\
\hline & 2.5 & 0.9 & & 0.8 & 0.45 & \\
\hline & 3.7 & 1.3 & & 1.4 & 0.6 & \\
\hline & 4.9 & 1.5 & & 2 & 0.7 & \\
\hline Cohesion force & \multicolumn{2}{|c|}{$232.6 \mathrm{kPa}$} & Cohesion force & \multicolumn{2}{|c|}{$210.5 \mathrm{kPa}$} & \multirow{6}{*}{$\mathrm{DK} 42+000$} \\
\hline Inner friction angle & \multicolumn{2}{|c|}{$15.05^{\circ}$} & Inner friction angle & \multicolumn{2}{|c|}{$14.42^{\circ}$} & \\
\hline \multirow{4}{*}{ \#3 } & 0.5 & 0.3 & \multirow{4}{*}{$\# 4$} & 0.6 & 0.35 & \\
\hline & 1.1 & 0.6 & & 1 & 0.5 & \\
\hline & 1.8 & 0.7 & & 2 & 0.7 & \\
\hline & 2.5 & 0.85 & & 2.8 & 0.9 & \\
\hline Cohesion force & \multicolumn{2}{|c|}{$231 \mathrm{kPa}$} & Cohesion force & \multicolumn{2}{|c|}{$228.7 \mathrm{kPa}$} & \\
\hline Inner friction angle & \multicolumn{2}{|c|}{$14.5^{\circ}$} & Inner friction angle & \multicolumn{2}{|c|}{$13.5^{\circ}$} & \\
\hline
\end{tabular}


and 12 , it can be seen that the shear stresses of test points \#1 2 linearly increase with the increase in the normal stress. The best-fitted expressions for the relationship between shear stress and normal stress of test points \#1 and \#2 are as follows:

$$
\begin{aligned}
& \tau_{(1)}=0.2689 \sigma_{(1)}+0.2326, \\
& \tau_{(2)}=0.2571 \sigma_{(2)}+0.2105,
\end{aligned}
$$

where $\tau_{(1)}$, and $\sigma_{(1)}$ are the shear stress and normal stress for test point $\# 1$ and $\tau_{(2)}$ and $\sigma_{(2)}$ are the shear stress and normal stress for test point \#2. According to the Coulomb criterion (equation (2)), the cohesive force of the test point \#1 is $232.6 \mathrm{kPa}$, and the internal friction angle is $15.05^{\circ}$. The cohesive force of the test point \#2 is $210.5 \mathrm{kPa}$, and the internal friction angle is $14.42^{\circ}$ :

$$
\tau_{\mathrm{n}}=C-\sigma_{\mathrm{n}} \tan \varphi,
$$

where $\tau_{\mathrm{n}}$ and $\sigma_{\mathrm{n}}$ are the shear stress and normal stress and $C$ and $\varphi$ are the cohesive force and internal friction angle, respectively.

3.3.2. Section of DK42+000. Figures 13 and 14 display the relationships between the shear stress and normal stress for test points \#3 and \#4. The shear stresses increase with the increase of normal stresses for test points \#3 and \#4, which are similar to \#1 2. The best-fitted expressions for the relationship between shear stress and normal stress of test points \#3 and \#4 are as follows:

$$
\begin{gathered}
\tau_{(3)}=0.2586 \sigma_{(3)}+0.231, \\
\tau_{(4)}=0.2399 \sigma_{(4)}+0.2287,
\end{gathered}
$$

where $\tau_{(3)}$ and $\sigma_{(3)}$ are shear stress and normal stress for test point \#3 and $\tau_{(4)}$ and $\sigma_{(4)}$ are shear stress and normal stress for test point \#4. The cohesive force and the internal friction angle of the test point $\# 3$ are $231 \mathrm{kPa}$ and $14.5^{\circ}$, respectively. The cohesive force and the internal friction angle of the test point $\# 4$ are $228.7 \mathrm{kPa}$ and $13.5^{\circ}$, respectively.

\subsubsection{Summary of Test Results for Borehole Shear Tests.} The results of the borehole shear test show that the cohesive force of the two sections that have been tested is between $210.5 \mathrm{kPa}$ and $232.6 \mathrm{kPa}$, and the internal friction angle is between $13.5^{\circ}$ and $15.05^{\circ}$. However, the cohesive force of the hard rock is more than $10 \mathrm{MPa}$, and the internal friction angle is more than $30^{\circ}$ [30]. In other words, the surrounding rock of the test section is seriously damaged, and its mechanical properties are similar to those of soils.

In addition, all the four data at a test point are obtained at a depth of 5 meters. The head of the rock borehole shear test apparatus is rotated $90^{\circ}$ after each shear, so the same depth is sheared by four times.

It is very urgent to improve the bearing capacity of the surrounding rock in the case of poor rock conditions. Therefore, it is recommended to grout before excavation, and the range of grouting should be larger than that of the broken rock zone.

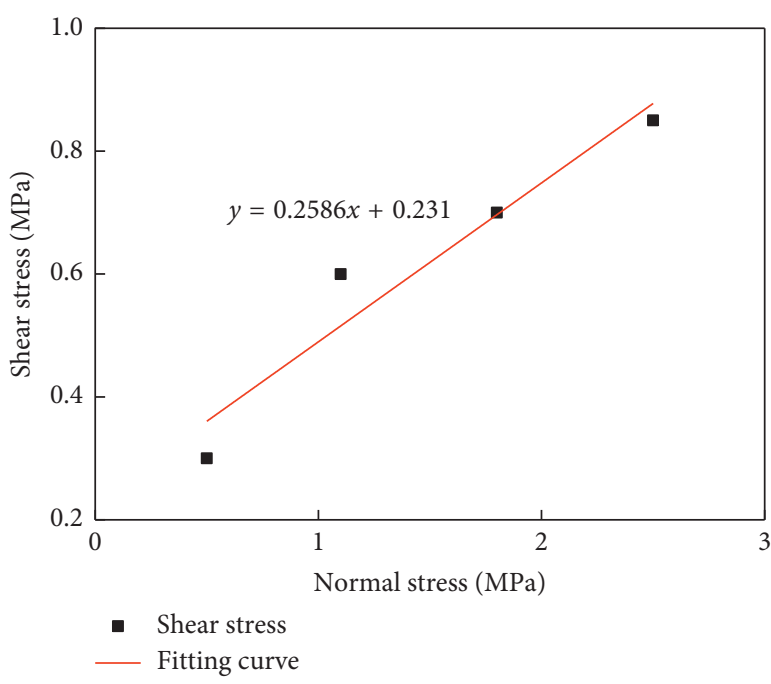

FIGURE 13: The relationship between the shear stress and the normal stress of the test point \#3.

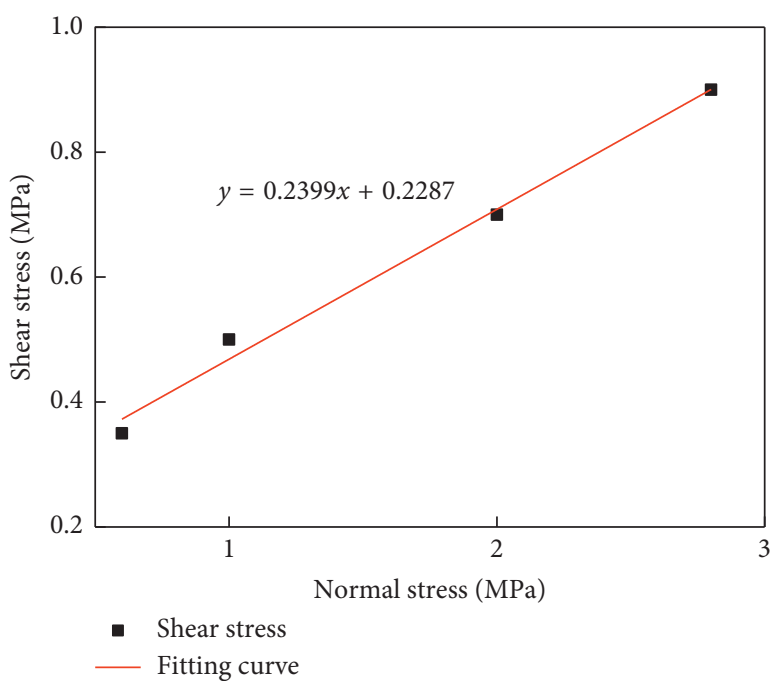

Figure 14: The relationship between the shear stress and the normal stress of the test point \#4.

\section{Conclusion and Support Recommendations}

In this study, a large deformation tunnel (Zhongyi tunnel) was taken for the engineering background, and the broken rock zone tests and the borehole shear tests were conducted. The relationship between the velocity of the longitudinal wave and the depth of the borehole, the shear stress, and the angle of internal friction of the original rock is analyzed and combined with the in situ tests and the site condition, and the suggestions for the tunnel support are put forward. The following conclusions are drawn:

(1) The broken rock zone of the Zhongyi tunnel is less than $4.5 \mathrm{~m}$, and the surrounding rock is extremely unstable. Therefore, the anchor cable is introduced to the support scheme of the tunnel. The cable size is selected as $22 \mathrm{~mm}$ in diameter and $5.5 \mathrm{~m}$ in length, and the spacing is set to $3 \mathrm{~m}$. 
(2) The cohesive force of the Zhongyi tunnel is less than $232.6 \mathrm{kPa}$, and the internal friction angle is less than $15.05^{\circ}$. Therefore, it is recommended to grout before excavation, and the range of grouting should be larger than that of the broken rock zone.

(3) The stress field of the surrounding rock changes after the excavation of the tunnel, and some of the arches have been distorted. It is necessary to replace the original support structure in addition to modification of the support scheme and the construction scheme.

\section{Data Availability}

The experimental and theoretical data used to support the findings of this study are available from the corresponding author upon request.

\section{Conflicts of Interest}

The authors declare that they have no conflicts of interest.

\section{Acknowledgments}

This study was supported by the National Natural Science Foundation of China (Grant nos. 51734009 and 51504247).

\section{References}

[1] G. Wu, S. Jia, W. Chen, J. Yuan, H. Yu, and W. Zhao, “An anchorage experimental study on supporting a roadway in steeply inclined geological formations," Tunnelling and Underground Space Technology, vol. 82, pp. 125-134, 2018.

[2] Y. Ge, H. Tang, D. Xia et al., "Automated measurements of discontinuity geometric properties from a 3D-point cloud based on a modified region growing algorithm," Engineering Geology, vol. 242, pp. 44-54, 2018.

[3] Y. Wu, F. Gao, J. Chen, and J. He, "Experimental study on the performance of rock bolts in coal burst-prone mines," Rock Mechanics and Rock Engineering, vol. 52, no. 10, pp. 1-12, 2019.

[4] M. Wang, D. Zheng, S. Niu, and W. Li, "Large deformation of tunnels in longwall coal mines," Environmental Earth Sciences, vol. 78, no. 2, p. 45, 2019.

[5] Y. Gao, H. W. Jing, S. J. Chen, M. R. Du, W. Q. Chen, and W. H. Duan, "Influence of ultrasonication on the dispersion and enhancing effect of graphene oxide-carbon nanotube hybrid nanoreinforcement in cementitious composite," Composites Part B: Engineering, vol. 164, pp. 45-53, 2019.

[6] H. Zhou, C.-k. Qu, D.-w. Hu et al., "In situ monitoring of tunnel deformation evolutions from auxiliary tunnel in deep mine," Engineering Geology, vol. 221, no. 4, pp. 10-15, 2017.

[7] T. Tjongkie, "Swelling rocks and stability of tunnels," Chinese Journal of Rock Mechanics and Engineering, vol. 2, no. 1, pp. 1-10, 1983.

[8] G. Anagnostou, "A model for swelling rock in tunnelling," Rock Mechanics \& Rock Engineering, vol. 26, no. 4, pp. 307331, 1993.

[9] B. Singh, R. K. Goel, J. L. Jethwa, and A. Dude, "Support pressure assessment in arched underground openings through poor rock masses," Engineering Geology, vol. 48, no. 1-2, pp. 59-81, 1997.
[10] Y. Jiang, H. Yoneda, and Y. Tanabashi, “Theoretical estimation of loosening pressure on tunnels in soft rocks," Tunnelling and Underground Space Technology, vol. 16, no. 2, pp. 99-105, 2001.

[11] H. Zhang, L. Chen, Y. Zhu, Z. Zhou, and S. Chen, "Stress field distribution and deformation law of large deformation tunnel excavation in soft rock mass," Applied Sciences, vol. 9, no. 5, p. 865, 2019.

[12] A. Yassaghi and H. Salari-Rad, "Squeezing rock conditions at an igneous contact zone in the Taloun tunnels, TehranShomal freeway, Iran: a case study," International Journal of Rock Mechanics and Mining Sciences, vol. 42, no. 1, pp. 95108, 2005.

[13] K. Bizjak and B. Petkovšek, "Displacement analysis of tunnel support in soft rock around a shallow highway tunnel at Golovec," Engineering Geology, vol. 75, no. 1, pp. 89-106, 2004.

[14] T. Janda, M. Šejnoha, and J. Šejnoha, “Applying Bayesian approach to predict deformations during tunnel construction," International Journal for Numerical and Analytical Methods in Geomechanics, vol. 42, no. 15, pp. 1765-1784, 2018.

[15] F. Dong, H. Song, Z. Guo, S. Lu, and S. Liang, "Roadway support theory based on broken rock zone," Journal of China Coal Society, vol. 19, no. 1, pp. 21-32, 1994.

[16] P. Cao, C. Chen, K. Zhang, C. Pu, and T. Liu, "Measurement and analysis of deep roadway surrounding rock loose zone in Jinchuan mine," Journal of Central South University, vol. 45, no. 8, pp. 2839-2844, 2014.

[17] W. Wang, D. Zhao, F. Gui, J. Deng, and B. Yan, "Research on safety of lining structure of railway tunnel with water leakage disease," China Safety Science Journal, vol. 26, no. 7, pp. 85-90, 2016.

[18] Y. Huang, J. S. Kou, H. B. Fang, M. L. Li, and Y. Liang, "Research on determination loose zone of surrounding rock in highway tunnel," Applied Mechanics and Materials, vol. 724, no. 1, pp. 185-191, 2015.

[19] H. Song, C. Wang, and Y. Jia, "Principle of measuring broken rock zone around underground roadway with GPR and its application," Journal of China University of Mining \& Technology, vol. 31, no. 4, pp. 370-373, 2002.

[20] H. Jing, Y. Li, J. Liang, and D. Yu, "Borehole camera technology for measuring the relaxation zone of surrounding rock: mechanism and application," Journal of China University of Mining \& Technology, vol. 38, no. 5, pp. 645-669, 2009.

[21] R. Handy and N. Fox, "A soil bore-hole direct shear test device," Highway Research News, vol. 27, pp. 42-51, 1967.

[22] A. Lutenegger and G. Hallberg, "Borehole shear test in geotechnical investigations," Astm Special Technical Publication, vol. 740, no. 13, pp. 566-578, 1981.

[23] J. Li, L. Kong, and K. Mu, "In-situ borehole shear test on expansive soil and its strength characteristics," Rock \& Soil Mechanics, vol. 38, no. 2, pp. 453-461, 2017.

[24] T. Bechtum, Automation and Further Development of the Borehole Shear Test, Iowa State University, Ames, Iowa, 2012.

[25] R. A. Lohnes and R. L. Handy, "Slope angles in friable loess," The Journal of Geology, vol. 76, no. 3, pp. 247-258, 1968.

[26] A. Lutenegger, B. Remmes, and R. Handy, "Borehole shear test for stiff soil," Journal of the Geotechnical Engineering Division, ASCE, vol. 104, no. GT11, pp. 1403-1407, 1978.

[27] G. Miller, S. Azad, and C. Hassell, "Iowa borehole shear testing in unsaturated soil," Geotechnical Site Characterization, vol. 2, no. 1, pp. 1321-1326, 1998. 
[28] V. Drnevich, A. Lutenegger, and D. Timian, "Reproducibility of borehole shear test results in marine clay," Geotechnical Testing Journal, vol. 10, no. 1, pp. 13-18, 1987.

[29] A. Lutenegger and M. Adams, "Tension tests on bored piles in residual soil," Geotechnical Special Publication, no. 92, pp. 43-53, 1999.

[30] N. Barton and V. Choubey, "The shear stress of rock joints in theory and practice," Rock Mechanics, vol. 10, no. 1-2, pp. 1-54, 1977. 


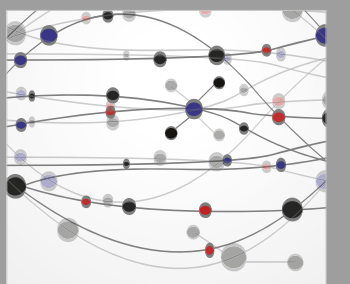

The Scientific World Journal
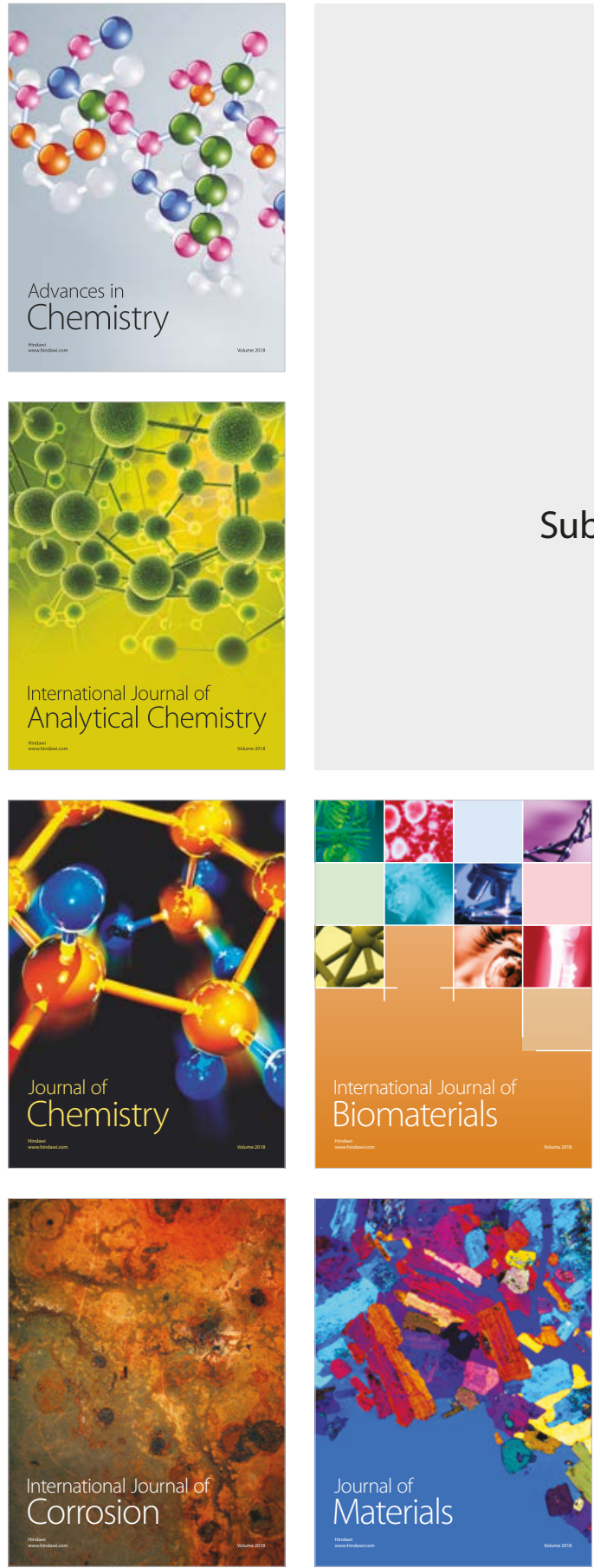

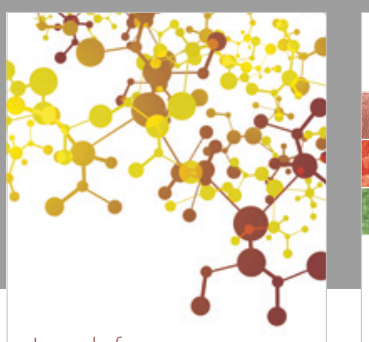

Journal of

Applied Chemistry
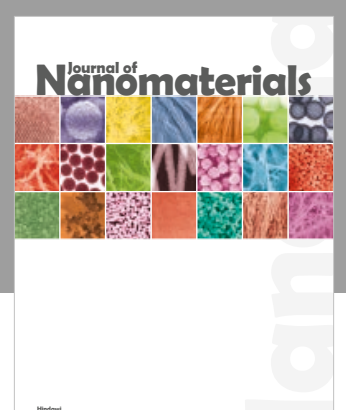

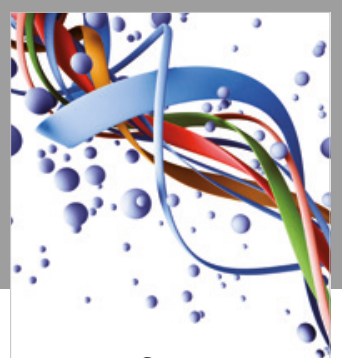

Scientifica

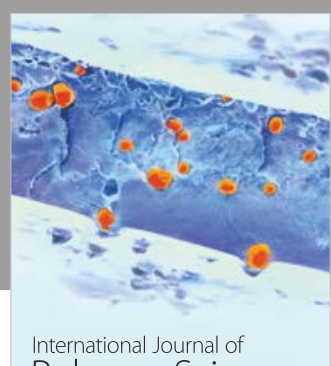

Polymer Science

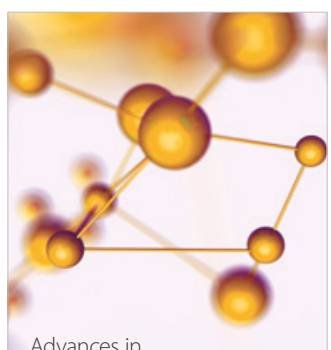

Physical Chemistry
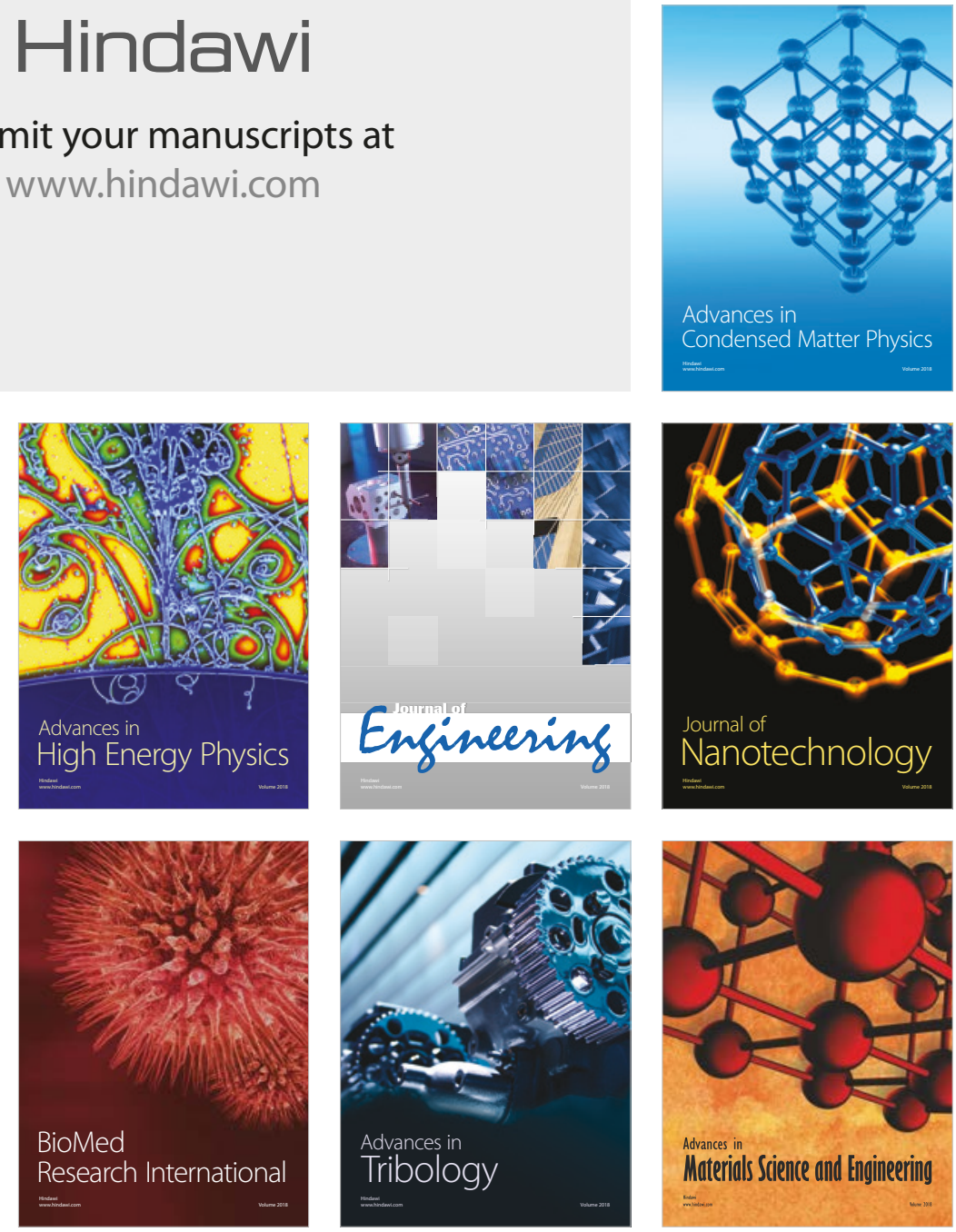